\title{
Morphological Differentiation Towards Neuronal Phenotype of SH-SY5Y Neuroblastoma Cells by Estradiol, Retinoic Acid and Cholesterol
}

\author{
Heidi Teppola $^{1} \cdot$ Jertta-Riina Sarkanen $^{2} \cdot$ Tuula O. Jalonen $^{3} \cdot$ Marja-Leena Linne $^{1}$
}

Received: 19 July 2015/Revised: 16 October 2015/Accepted: 17 October 2015/Published online: 30 October 2015

(c) The Author(s) 2015. This article is published with open access at Springerlink.com

\begin{abstract}
Human SH-SY5Y neuroblastoma cells maintain their potential for differentiation and regression in culture conditions. The induction of differentiation could serve as a strategy to inhibit cell proliferation and tumor growth. Previous studies have shown that differentiation of SH-SY5Y cells can be induced by all-trans-retinoic-acid (RA) and cholesterol (CHOL). However, signaling pathways that lead to terminal differentiation of SH-SY5Y cells are still largely unknown. The goal of this study was to examine in the RA and CHOL treated SH-SY5Y cells the additive impacts of estradiol $\left(\mathrm{E}_{2}\right)$ and brain-derived neurotrophic factor (BDNF) on cell morphology, cell population growth, synaptic vesicle recycling and presence of neurofilaments. The above features indicate a higher level of neuronal differentiation. Our data show that treatment for 10 days in vitro (DIV) with RA alone or when combined with $\mathrm{E}_{2}$ (RE) or CHOL (RC), but not when combined with BDNF (RB), significantly $(p<0.01)$ inhibited the cell population growth. Synaptic vesicle recycling, induced by high- $\mathrm{K}^{+}$depolarization, was
\end{abstract}

Tuula O. Jalonen and Marja-Leena Linne are Co-senior authors.

Heidi Teppola

heidi.teppola@tut.fi

1 Department of Signal Processing, Tampere University of Technology, P.O. Box 553, 33101 Tampere, Finland

2 Department of Cell Biology, School of Medicine, University of Tampere, Tampere, Finland

3 Department of Physiology and Neuroscience, St. George's University School of Medicine, St. George's,

Grenada, West Indies significantly increased in all treatments where RA was included (RE, RC, RB, RCB), and when all agents were added together (RCBE). Specifically, our results show for the first time that $E_{2}$ treatment can alone increase synaptic vesicle recycling in SH-SY5Y cells. This work contributes to the understanding of the ways to improve suppression of neuroblastoma cells' population growth by inducing maturation and differentiation.

Keywords Brain-derived neurotrophic factor .

Cholesterol · Differentiation - Estradiol - Retinoic acid . SH-SY5Y

\begin{tabular}{|c|c|}
\hline \multicolumn{2}{|c|}{ Abbreviations } \\
\hline AChE & Acetylcholinesterase \\
\hline Arc & $\begin{array}{l}\text { Activity-regulated cytoskeleton associated } \\
\text { protein }\end{array}$ \\
\hline BDNF & Brain-derived neurotrophic factor \\
\hline $\mathrm{CHOL}$ & Cholesterol \\
\hline $\mathrm{CO}_{2}$ & Carbon dioxide \\
\hline CTNF & Corrected total neurofilament fluorescence \\
\hline DIV & Days in vitro \\
\hline $\mathrm{E}_{2}$ & Estradiol \\
\hline ER & Estrogen receptor \\
\hline LTP & Long-term potentiation \\
\hline NF-68 & Neurofilament 68 kD \\
\hline PBS & Phosphate-buffered saline \\
\hline RA & All-trans retinoic acid \\
\hline $\mathrm{RB}$ & All-trans retinoic acid with BDNF \\
\hline $\mathrm{RC}$ & All-trans retinoic acid with $\mathrm{CHOL}$ \\
\hline $\mathrm{RCB}$ & All-trans retinoic acid with $\mathrm{CHOL}$ and $\mathrm{BDNF}$ \\
\hline $\mathrm{RCBE}$ & All-trans retinoic acid with $\mathrm{CHOL}, \mathrm{BDNF}$ and $\mathrm{E}_{2}$ \\
\hline $\mathrm{RE}$ & All-trans retinoic acid with $E_{2}$ \\
\hline RT & Room temperature \\
\hline TrkB & Tropomyosin-related kinase B \\
\hline
\end{tabular}




\section{Introduction}

Neuroblastoma is the most common extra-cranial solid malignant tumor of sympathetic nervous system in infants and young children [1]. Regardless of its stage, until today, there is no cure or treatment, which could offer good prognosis for patients [2, 3]. Human SH-SY5Y cell line, used in this study, is a subclone of SK-N-SH cell line which was isolated from a bone marrow of a 4 year-old female patient [4]. SH-SY5Y cells maintain their potential for regression, which results in aggressive proliferation of these cells [5]. Novel therapeutic treatments inducing differentiation into neuronal cell types could help to improve the prognosis of children suffering from neuroblastoma [6]. The induction of differentiation could serve as a strategy to inhibit cell population growth and eventually stop the tumor growth, as well as induce healthy mature neurons in patients.

Previous studies have presented that differentiation of SH-SY5Y cells can be induced by dibutyryl cyclic AMP [5, 7], 12-o-tetradecanoyl-phorbol-13-acetate [8-13], alltrans-retinoic-acid (RA) [9, 14-16], brain-derived neurotrophic factor (BDNF) [17-19], vanadate [20], nerve growth factor [21, 22], cholesterol (CHOL) [23], vitamin D3, and neuregulin beta1 [24]. The signaling pathways that lead to terminal differentiation of SH-SY5Y cells, however, are still largely unknown.

The retinoic acid (RA) is a potent cell differentiating factor, which through its nuclear receptors affects a vast range of promoter sites in the neuronal and glial cells in every step of embryonic and postnatal life [25]. RA-induced differentiation has been shown to inhibit cell proliferation [9], change cellular sodium conductance [15], enhance the outgrowth of neurites [16], increase the acetylcholinesterase (AChE) activity [26, 27], and enhance the synaptic vesicle recycling [23]. However, clinical trials have demonstrated that treatment with RA alone, or in combination with interferon alpha, is not enough against recurrent neuroblastoma in children [28, 29]. Therefore, new alternative resources for more effective neuronal differentiation are needed.

Cholesterol (CHOL) is a necessary component in cell membranes and important for synaptic structure and function [30]. It is synthesized by neurons themselves for their survival and growth. The development of active synapses requires additional amount of cholesterol that is shown to be secreted by glial cells (specifically astrocytes) in the central nervous system [30-32] and by Schwann cells in the peripheral nervous system [33]. The gliaderived cholesterol has also been shown to be crucial for differentiation of dendrites, synaptogenesis, increase in synaptic protein expression (synapsin-1) and neuronal activity, and for transmitter release [30, 32, 34, 35]. In pure human SH-SY5Y cell cultures, the glia-derived cholesterol is non-existing, and addition of cholesterol is needed in order to achieve conditions resembling normal neuronal environment with surrounding glial cells [23].

The brain-derived neurotrophic factor (BDNF) has been shown to support the survival of neurons and stimulate the growth and differentiation of new neurons and synapses [36]. BDNF is a ligand for tropomyosin-related kinase B (TrkB) receptor, expression of which is lacking in naïve neuroblastoma cells. However, TrkB receptor expression and responsiveness to BDNF is induced by RA [37]. The activation of TrkB by BDNF has been suggested to enhance neuroblastoma cell survival and resistance to chemotherapy [38]. BDNF has also been shown to expose only a modest benefit for RA-induced arrest in a dormant state [6]. However, the sequential treatment of SH-SY5Y cells with RA and BDNF has been reported to induce differentiated, neurotrophic factor-dependent neuron-like cells [18] and sustained treatment has been reported to enhance neuronal differentiation of neural progenitor cells [39]. Moreover, RA-BDNF treatment induces significant increase in the expression of synaptic genes, brain miRNA, miRNA biogenesis machinery, and AChE activity, in comparison to sole RA treatment [19]. These studies stimulate the interest to further examine the potential therapeutic competence of BDNF for RA-induced SHSY5Y cell differentiation and for treatment of neuroblastoma. Disruption of BDNF and its downstream signaling pathways have been observed in many neurodegenerative diseases such as Alzheimer's, Parkinson's and Huntington's diseases [40-42], underlining the importance of BDNF. However, the results of the role of added exogenous BDNF for differentiation of RA treated SH-SY5Y cells are still controversial.

Estradiol (17-beta-estradiol, $\mathrm{E}_{2}$ ), a form of estrogen hormone, has both acute and long-term effects on a variety of neuronal cell types. Increase in the number of dendritic spines and number of excitatory synapses, which are the slow long-term effects of estradiol, were first detected [4345]. The acute effects, which alter the intrinsic and synaptic physiology of neurons within minutes (reversible depolarization and increased input resistance with a latency of $<1 \mathrm{~min}$ in $19.8 \%$ of CA1 neurons tested) were detected later [46, 47]. Several studies have shown that estrogen enhances synaptogenesis and synaptic plasticity [48-55], which properties may be crucial for example in enhancing memory consolidation $[43,56]$. Additionally, estrogen has been demonstrated to induce synaptic connectivity [52], enhance NMDA receptor expression and activity [57-66], and long-term potentiation (LTP) [58, 59, 64, 67]. Several earlier studies have addressed possible signaling 
mechanisms associated with estrogen-induced cellular functions. Estrogen activates these functions through the activation of estrogen receptors (ERs), ER $\alpha$ and ER $\beta$, which serve as transcription factors modifying the activity of target genes [68, 69]. Estrogen has been shown to increase the key synaptic proteins, e.g. PSD-95, via either activation of ER $\alpha$ [70], ER $\beta$ [51], or both [71]. Estrogen is thought to use both nuclear ERs and plasma membrane ERs which are usually referred to as classical genomic and non-genomic pathways [69]. In classical genomic action, ERs are thought to translocate into nucleus in ligand-dependent manner and acting as a transcription factor of target genes after prolonged estrogen exposure [72]. In non-genomic action, estrogen has been shown to activate the membrane ERs, which rapidly stimulate the membraneassociated signaling molecules such as PI-3K and MAPK, resulting in quick increase in protein expression [73, 74]. SH-SY5Y cells have been shown to express both ER $\alpha$ and ER $\beta$ [75]. Estrogen has also been shown to stimulate the activity-regulated cytoskeleton associated protein (Arc) expression via the MAPK and PI-3K dependent pathway in SH-SY5Y cells [48]. Arc is known to be induced by neuronal activity and playing a key role in activity-dependent synaptic plasticity [76]. Its knockdown has been shown to lead to impairment of long-term memory [77, 78]. However, the specific role of $E_{2}$ for inducing differentiation in human SH-SY5Y neuroblastoma cells is still unknown.

The main goal of the current study was to find a functional combination of substances for effective induction of differentiation of the SH-SY5Y cells. Based on our earlier studies, we used RA and CHOL as primary differentiation treatments [23]. We further investigated the ability of $\mathrm{E}_{2}$ and BDNF to support, and possible enhance, the RA and CHOL induced neuronal differentiation. We quantified the individual and additive impacts of BDNF and $\mathrm{E}_{2}$ on the RA and CHOL-induced neurite outgrowth, presence of neurofilament 68 , synaptic vesicle recycling and arrest in the population growth rate of SH-SY5Y neuroblastoma cells in vitro.

\section{Methods}

\section{Maintenance and Differentiation of Cell Cultures}

The human SH-SY5Y neuroblastoma cell line (CRL-2266; American Type Culture Collection, Manassas, VA, USA) was cultured as previously described [23]. Briefly, the cells were plated at passage 29-30 with density of 5000 cells/ $\mathrm{cm}^{2}$ on 48-well culture dishes. Cells were cultured and maintained in $5 \% \mathrm{CO}_{2}$ humidified incubator at $37{ }^{\circ} \mathrm{C}$ in 1:1 nutrient mixture F-12K Kaighn's modification, and minimum essential medium supplemented with $10 \%$ fetal bovine serum, $2 \mathrm{mM} / \mathrm{L}$ L-glutamine, $1 \%$ antibiotic-antimycotic mixture and $1 \%$ non-essential amino acids (all reagents from GIBCO, Invitrogen, Carlsbad, CA, USA, unless otherwise stated). Cell differentiation was induced with $10 \mu \mathrm{M} / \mathrm{L}$ all-trans retinoid-acid (RA), $1 \mathrm{nM} / \mathrm{L}$ 17-beta-estradiol $\left(\mathrm{E}_{2}\right), \quad 50 \mathrm{ng} / \mathrm{mL}$ brain-derived neurotrophic factor (BDNF), $10 \mu \mathrm{g} / \mathrm{mL}$ cholesterol (3ß-hydroxy-5-cholestene, $\mathrm{CHOL}$ ), or with combinations such as (i) $5 \mu \mathrm{M} / \mathrm{L}$ RA with $5 \mu \mathrm{g} / \mathrm{mL}$ CHOL (RC), (ii) $5 \mu \mathrm{M} / \mathrm{L}$ RA with $50 \mathrm{ng} / \mathrm{mL}$ BDNF (RB), (iii) $5 \mu \mathrm{M} / \mathrm{L}$ RA with $1 \mathrm{nM} / \mathrm{L}$ $\mathrm{E}_{2}$ (RE), (iv) $5 \mu \mathrm{M} / \mathrm{L}$ RA with $5 \mu \mathrm{g} / \mathrm{mL} \mathrm{CHOL}$, and $50 \mathrm{ng} /$ $\mathrm{mL}$ BDNF (RCB), and (v) $5 \mu \mathrm{M} / \mathrm{L}$ RA with $5 \mu \mathrm{g} / \mathrm{mL}$ CHOL, $50 \mathrm{ng} / \mathrm{mL}$ BDNF, and $1 \mathrm{nM} / \mathrm{L} \mathrm{E}_{2}$ (RCBE) for 10 DIV (all differentiation reagents from Sigma-Aldrich, St Louis, MO, USA, unless otherwise stated). Stock solutions of differentiation substances were diluted in $96 \%$ ethanol; the final ethanol concentration never exceeded $0.1 \%$ in cell culture. Control cells were treated with $<0.1 \%$ ethanol. All used substance concentrations were carefully evaluated according to already published literature. Suitable, least toxic concentrations, also used by other laboratories, were used to enable comparison of our results with others. All differentiation substances (except BDNF when used in combinations) were applied with medium exchange at 1, 3 and 7 DIV. BDNF was applied at 4 and 7 DIV when used together with RA (RB), RA and CHOL (RCB) or RA, CHOL and $\mathrm{E}_{2}$ (RCBE). The cell growth, condition, and morphology were observed with culture microscope (Olympus CK40) and images were taken at 10 DIV DP10 microscope digital camera system (Olympus, Tokyo, Japan).

\section{Neurofilament Staining}

For detecting the level of differentiation in the neuroblastoma cell cultures, the cells were stained at 10 DIV with neuronal marker NF-68 for neurofilament light polypeptide (68 kDa, Sigma-Aldrich). Cells were first fixed for $20 \mathrm{~min}$ with $4 \%$ paraformaldehyde (Sigma-Aldrich) in phosphate buffered saline solution (PBS), washed three times with PBS and permeabilized in $0.5 \%$ Triton X-100 (J.T. Baker, Phillipsburg, NJ, USA) for $15 \mathrm{~min}$. After washing with PBS, the non-specific antibody binding sites were blocked with $10 \%$ bovine serum albumin (GIBCO) in PBS for $30 \mathrm{~min}$ to reduce the background. Cells were then incubated with the primary antibody mouse monoclonal antiNF-68 1:200 for $1 \mathrm{~h}$ at room temperature (RT; $+22{ }^{\circ} \mathrm{C}$ ), rinsed three times with PBS, and then incubated with a secondary antibody FITC-conjugated goat anti-mouse IgG 1:100 (Sigma-Aldrich) for $30 \mathrm{~min}$ at RT. Fluorescence was visualized with Nikon Eclipse TS100 microscope equipped with Nikon DS Camera Control Unit DS L-1 and images were organized with Visio 2010 (Microsoft, WA, USA). 
The intensity of total neurofilament fluorescence (NF-68) and the intensity of total background fluorescence were measured from each fluorescence image with ImageJ software (National Institute of Mental Health, Bethesda, Maryland, USA) [79]. Corrected total neurofilament fluorescence (CTNF) was calculated from the gathered data in Excel 2010 (Microsoft, WA, USA) with the method used previously [80, 81], as follows: The fluorescence of the neurofilaments of interest was selected using the selection tool. Area of interest, integrated density, and mean gray value were calculated from selected areas with ImageJ software. A region next to the selected neurofilament was selected as a background value. The CTNF was calculated by using the following equation CTNF = integrated density - (area of selected neurofilaments $\times$ mean fluorescence of background readings).

\section{Quantification of Cell Population Growth}

The substance-induced changes in the growth rate were quantified by counting the nuclei of 10 DIV cultured SHSY5Y cells in each treatment group. Cell nuclei were stained with $10 \mu \mathrm{g} / \mathrm{mL}$ Hoechst 33258 (Sigma-Aldrich) for $5 \mathrm{~min}$. Cultures were washed five times in PBS and mounted on cover slips. Fluorescence results were visualized with Nikon DS Camera Control Unit DS L-1. Images of each treatment group were analyzed with CellC analysis software [82], which corrects the image background for auto-fluorescence by fitting a two-dimensional quadratic polynomial to the image and subtracts the fitted polynomial surface from the original image. After this the algorithm separates the nuclei pixels from background pixels by global thresholding and produces a binarized image with white nuclei on a black background. It furthermore separates clustered nuclei from each other by marker-controlled watershed segmentation, which is based on nuclei intensity. Eventually the software removes artifacts, such as staining residues by discarding objects smaller than $1 / 10$ of the mean size of all objects. Images were organized with Microsoft Visio 2010. The obtained nuclei counts and statistics (see section "Statistical Analysis") were analyzed and plotted in MATLAB (version 2013b, The Mathworks Inc., MA, USA).

\section{Quantification of Neurite Length}

The SH-SY5Y cells were cultured in CTRL, CHOL, $\mathrm{E}_{2}$, BDNF, RA, RE, RB, RC and RCBE conditions at 10 DIV. Neurites were traced from phase contrast images of each treatment group with NeuronGrowth plugin [83] of the ImageJ software (National Institute of Mental Health, Bethesda, Maryland, USA) [79]. The NeuronGrowth automatically counts the length of traced neurites in pixels and exports the data. The gathered data and statistics were analyzed and plotted in MATLAB (version 2013b, The Mathworks Inc., MA, USA).

\section{Synaptic Vesicle Recycling}

The level of synaptic vesicle recycling was verified by measuring the number of fluorescence puncta in 10 DIV cultured SH-SY5Y cells. Cells were treated either with $<0.1 \%$ ethanol (CTRL), RA, CHOL, BDNF, $\mathrm{E}_{2}$, or with their combinations. Cultures were stained with AM1-43 styryl dye (Biotium, Hayward, CA, USA) for detecting synaptic exo/endocytosis in cells. AM1-43 is a fixable nerve terminal probe. It is not able to pass through the membranes, but instead, when cells are depolarized with high potassium $\left(\mathrm{K}^{+}\right)$-Tyrode solution, AM1-43 styryl dye attaches inside those vesicles, which are ongoing exocytosis. Staining was modified from method previously described $[23,84,85]$. In the current experiments, the cells were incubated for $1 \mathrm{~min}$ with $4 \mu \mathrm{mol} / \mathrm{L}$ AM1-43, according to manufacturer's protocol, with the depolarizing Tyrode solution including $80 \mathrm{mmol} / \mathrm{L} \mathrm{K}^{+}(80 \mathrm{mmol} / \mathrm{L}$ $\mathrm{KCl}, 29 \mathrm{mmol} / \mathrm{L} \mathrm{NaCl}, 2 \mathrm{mmol} / \mathrm{L} \quad \mathrm{MgCl}_{2}, 30 \mathrm{mmol} / \mathrm{L}$ glucose, $25 \mathrm{mmol} / \mathrm{L}$ HEPES, $2 \mathrm{mmol} / \mathrm{L} \mathrm{CaCl}_{2}$ ). Cells were further washed several times with SCAS quencher solution (Biotium, Hayward, CA, USA) at RT to reduce background fluorescence. Cells were fixed for $20 \mathrm{~min}$ with $4 \%$ paraformaldehyde (GIBCO), permeabilized in $0.01 \%$ Triton X-100 (J.T. Baker) for $12 \mathrm{~min}$ and washed three times for $1 \mathrm{~min}$ in cold PBS. All reagents were from Sigma Aldrich unless otherwise stated. The fluorescence was visualized with Nikon Eclipse TS100 microscope equipped with Nikon DS Camera Control Unit DS L-1 and images were organized with Microsoft Visio 2010. Fluorescence images of each treatment group were analyzed with ImageJ analysis software [79] using the following procedural steps specifically designed to this study: background of the image was subtracted by setting a rolling ball radius to 50 pixels, after image was sharpened, and then the maxima of fluorescence puncta were found with noise tolerance of 20 and with the point selection style. This procedure was evaluated by visual inspection and it was found to be the best for finding the correct number of AM1-43 puncta from fluorescence images. The obtained counts of fluorescence puncta per image were divided by the obtained median nuclei number (see section "Quantification of Cell Population Growth") in particular culture in 10 DIV treatments. These obtained counts of fluorescence puncta per median nuclei number and statistics (see section "Statistical Analysis") were analyzed and plotted in MATLAB (version 2013b). 
Table 1 Summary of differentiation

\begin{tabular}{|c|c|c|c|c|}
\hline Treatment $^{\dagger}$ & Neurite length & Total neurofilament fluorescence & Inhibition of cell population growth & Synaptic vesicle recycling \\
\hline CTRL & - & - & - & - \\
\hline CHOL & $++* *$ & - & - & - \\
\hline $\mathrm{E}_{2}$ & $+^{*}$ & - & - & $+^{*}$ \\
\hline BDNF & - & - & - & - \\
\hline RA & $+++* *$ & $+++* *$ & $+++* *$ & $++* *$ \\
\hline $\mathrm{RE}$ & $+++* *$ & $++*$ & $+++* *$ & $++* *$ \\
\hline $\mathrm{RC}$ & $+++* *$ & $+++* *$ & $+++* *$ & $+++^{*}$ \\
\hline $\mathrm{RB}$ & $+++* *$ & $+++* *$ & ++ & $++^{* *}$ \\
\hline $\mathrm{RCB}$ & $+++* *$ & * & $*$ & $+++^{*}$ \\
\hline RCBE & $+++* *$ & $+++* *$ & $\star$ & $+++^{*}$ \\
\hline
\end{tabular}

The criteria for categorizing the neurite length were as follows: - neurites similar to control, + short neurites without branching and significantly longer than in control $\left[p<0.05\left(^{*}\right)\right],++$ intermediate neurites without branching and significantly longer than in control $[p<0.01(* *)]$, +++ long neurites with branching and significantly longer than in control $[p<0.01(* *)]$ and in $\mathrm{CHOL}$ or $\mathrm{E}_{2}$ treatment conditions $[p<0.01$ $(* *)$ ]. The criteria for categorizing the total neurofilament fluorescence were as follows: - no neurofilament fluorescence, ++ significantly $[p<0.05(*)]$ increased neurofilament fluorescence compared to control, +++ significantly $[p<0.01(* *)]$ increased neurofilament fluorescence compared to control. The criteria for categorizing the inhibition of cell population growth were as follows: - the number of cells has not changed after the treatment, ++ the number of cells decreased (not significantly), +++ the number of cells significantly $[p<0.01(* *)]$ decreased. The criteria for categorizing the amount of synaptic vesicle recycling were as follows: - no significant change in the counts of puncta in comparison to control, + significant $[p<0.05(*)]$ increase in the counts of fluorescence puncta in comparison to control, ++ significant $\left[p<0.01\left(^{* *}\right)\right]$ increase in the counts of fluorescence puncta in comparison to control, +++ significant $[p<0.05(*)]$ increase in the counts of fluorescence puncta in comparison to $\mathrm{RE}$ and $\mathrm{RB}$

${ }^{\dagger}$ Control (CTRL, $<0.1 \%$ ethanol), cholesterol (CHOL; $\left.10 \mu \mathrm{g} / \mathrm{ml}\right)$, 17-beta-estradiol $\left(\mathrm{E}_{2} ; 1 \mathrm{nM} / \mathrm{L}\right)$, brain derived neurotrophic factor (BDNF; $50 \mathrm{ng} / \mathrm{mL}$ ), all-trans retinoic acid (RA; $10 \mu \mathrm{g} / \mathrm{mL}$ ), RA with $\mathrm{E}_{2}$ (RE; RA $5 \mu \mathrm{g} / \mathrm{mL}, \mathrm{E}_{2} 1 \mathrm{nM} / \mathrm{L}$ ), RA with CHOL (RC; RA $5 \mu \mathrm{g} / \mathrm{mL}, \mathrm{CHOL} 5 \mu \mathrm{g} /$ $\mathrm{mL}$ ), RA with BDNF (RB; RA $5 \mu \mathrm{g} / \mathrm{mL}$, BDNF $50 \mathrm{ng} / \mathrm{mL}$ ), RA with CHOL and BDNF (RCB; RA $5 \mu \mathrm{g} / \mathrm{mL}, \mathrm{CHOL} 5 \mu \mathrm{g} / \mathrm{mL}, \mathrm{BDNF} 50 \mathrm{ng} /$ $\mathrm{mL}$ ), RA with CHOL, BDNF and $\mathrm{E}_{2}$ (RCBE; RA $5 \mu \mathrm{g} / \mathrm{mL}$, CHOL $5 \mu \mathrm{g} / \mathrm{mL}$, BDNF $50 \mathrm{ng} / \mathrm{mL}, \mathrm{E}_{2} 1 \mathrm{nM} / \mathrm{L}$ )

* Conclusive data not available

\section{Summary of the Level of Differentiation}

Results are summarized in Table 1, which shows the level of differentiation induced by different treatments. The level of differentiation was assessed at least from three samples from two separate experiments by analyzing the following features; neurite length, presence of neurofilaments, inhibition in cell population growth rate and synaptic vesicle recycling. Neurite lengths were detected both visually and, by using automated methods to support the visual detection. Other features were defined according to the methods explained above (see sections "Neurofilament Staining, Quantification of Cell Population Growth and Synaptic Vesicle Recycling").

\section{Statistical Analysis}

Statistical analysis was performed using One-way ANOVA in MATLAB (version 2013b). Differences were considered to be significant when $p<0.01$ or $p<0.05$, different significances are indicated with $* *$ or $*$ in the figures, respectively.

\section{Results}

\section{Morphology of Differentiated SH-SY5Y Cells}

Phase contrast images of SH-SY5Y cultures at 10 DIV were first visually analyzed for morphological assessment. In the visual analysis, control cells showed no particular neurite outgrowth (Fig. 1a), whereas CHOL-treated cells had a number of short neurites (green arrows in Fig. 1b; see also Table 1). Cells treated with $E_{2}$ had very short neurites (Fig. 1c), which were both fewer and shorter than the CHOL-induced neurites. The morphology of BDNF treated SH-SY5Y was relatively polar and cells grew more spread in the culture dish (Fig. 1d). This differed from control cells, which grew in clusters (Fig. 1a). No significant outgrowth of neurites was observed after BDNF treatment. Treatment with RA alone (Fig. 1e) as well as with combinations such as RE, RB, RC, RCB or RCBE, induced branching of longer neurites and detectable network formation (Fig. 1f $-\mathrm{j}$, respectively).

The data show other morphological differences between the treatments as well. The RE treated SH-SY5Y cells had 
Fig. 1 Morphology and network formation of SH-SY5Y neuroblastoma cells at $10 \mathrm{DIV}$. a SH-SY5Y cells were grown for 10 DIV in control conditions (CTRL) and with $\mathbf{b}$ cholesterol (CHOL), c estradiol $\left(\mathrm{E}_{2}\right)$, d brain-derived neurotrophic factor (BDNF), e all-trans retinoic-acid (RA), or with their combinations $\mathbf{f}-\mathbf{j}$ RE, RB, RC, RCB, RCBE, respectively. Data show that the CHOL treatment induced short neurites (green arrows) with many varicosities (red arrows) (b). $\mathrm{E}_{2}$ induced few very short neurites in comparison to $\mathrm{CHOL}$ induced neurites (c). BDNF treatment did not induce significant growth of neurites or network formation (d). RA treatment generated thin branching neurites and promoted network formation (blue arrows, e). Networks of cells with cell-to cell contacts (blue arrows) were always detected when treated with RA together with $\mathbf{f} E_{2}$ (RE), g BDNF (RB), h CHOL (RC), i CHOL and BDNF (RCB), and $\mathbf{j}$ CHOL, BDNF, and $\mathrm{E}_{2}$ (RCBE). Flat substrateadherent (S-type) cells were detected especially when cells were treated with $\mathrm{E}_{2}$ or BDNF (orange arrows) $(\mathbf{c}, \mathbf{d})$ but also when cells were treated with RE (data not shown) or RB (orange arrows) (g). The RE treated cells (f) had thinner neurites than those treated with RCBE (j) (Color figure online)
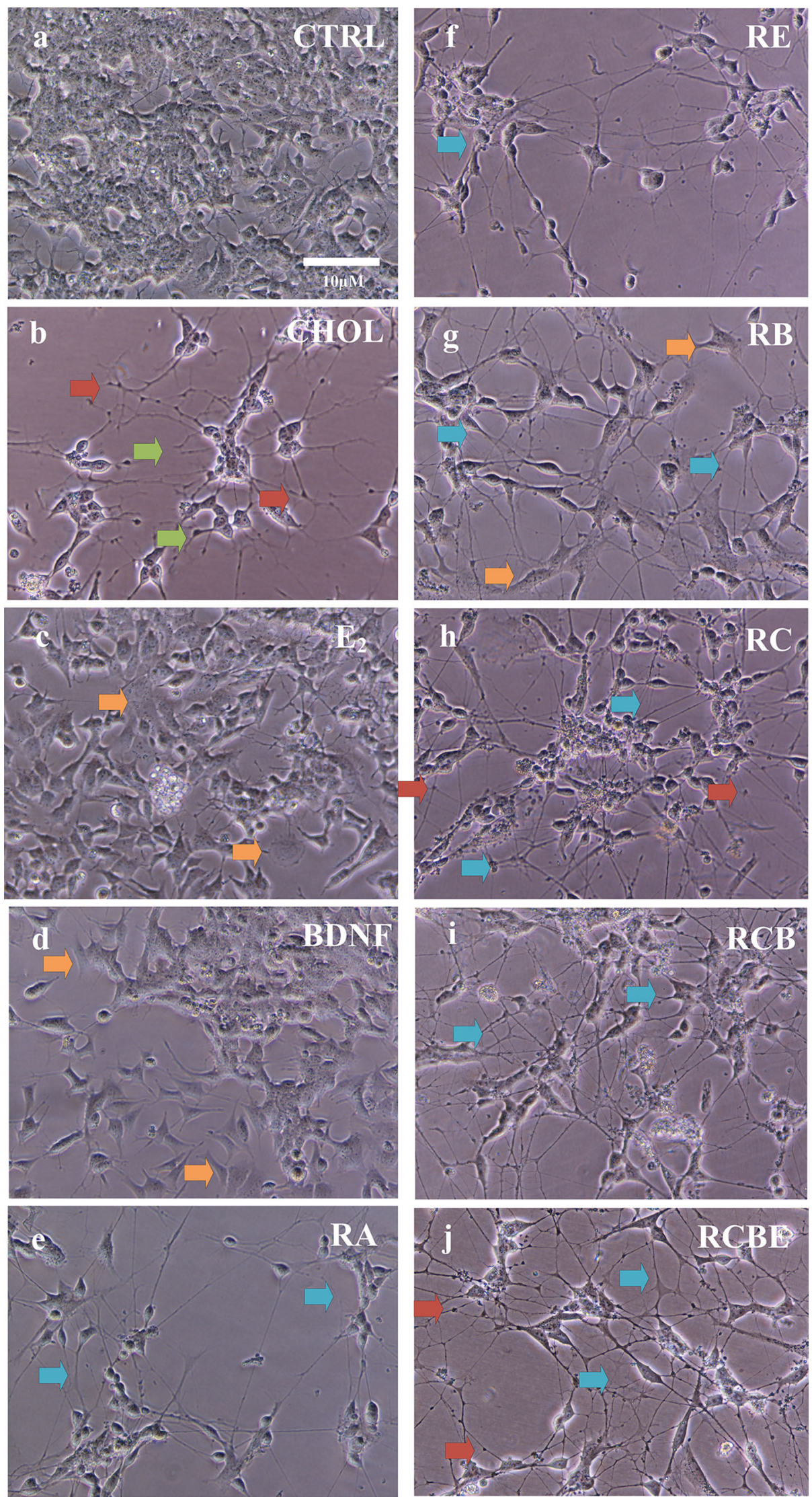
networks of roundish cells with thin neurites without heavy branching (Fig. 1f). A small number of substrate-adherent (S-type) flat cells [86] were observed in cultures treated with RE (data not shown), RB (orange arrows in Fig. 1g) and RA (data not shown). The RB treatment induced networks that consisted of extended contacting neurites, as well as of cells in direct contact with each other without neurites. The neurites of the RB treated cells were thicker in comparison to RE induced neurites. The RC treatment induced cells with long, branching and connecting neurites (blue arrows in Fig. 1h). Other cholesterol treated cultures, such as RCB and RCBE, contained neurons with long branching neurites and network formation without S-type cells. More varicosities (red arrows in Fig. 1b) and small cell clusters (data not shown) were observed in CHOL treated cultures (CHOL, RC, RCB, RCBE) in comparison to the control, $\mathrm{RE}$ and $\mathrm{RB}$ treated groups, in which cells were more uniformly distributed (data not shown).

\section{Inhibition of Cell Population Growth}

The ability of a substance to inhibit the population growth of human SH-SY5Y cells is one of the indicators of increased level of differentiation. Therefore, we counted the numbers of the Hoechst 33258 stained nuclei at 10 DIV in RA, CHOL, BDNF, $\mathrm{E}_{2}, \mathrm{RE}, \mathrm{RB}$, and $\mathrm{RC}$ treated cell cultures and compared the results to the number of nuclei in control conditions. The data demonstrated that CHOL, $\mathrm{E}_{2}$ or BDNF treatments on their own did not inhibit the cell population growth (Fig. 2), which, however, was seen when treated with RA, as well as with RA together with CHOL (RC) $[p<0.01(* *)]$ when compared to controls. Moreover, significant $(p<0.01(* *)$ inhibition was also detected with RA together with $\mathrm{E}_{2}(\mathrm{RE})$ treatment, when compared to controls (Fig. 2). Interestingly, when cells were treated with RA and BDNF, no inhibition of growth was detected (Fig. 2).

\section{Neurite Lengths}

The neurites of SH-SY5Y cells were traced from phase contrast images taken from each experiment at 10 DIV with NeuronGrowth (see section "Methods"), which provides supportive information of the lengths in addition to the visual inspection of the cell morphology. In addition to RA $[p<0.01(* *)]$, also with CHOL alone $[p<0.01(* *)]$ and $\mathrm{E}_{2}$ alone $[p<0.05(*)]$ treatments, induced a significant increase in the length of neurites in comparison to control cells at 10 DIV (Fig. 3). Furthermore, the significant increase in the neurite length was seen in all

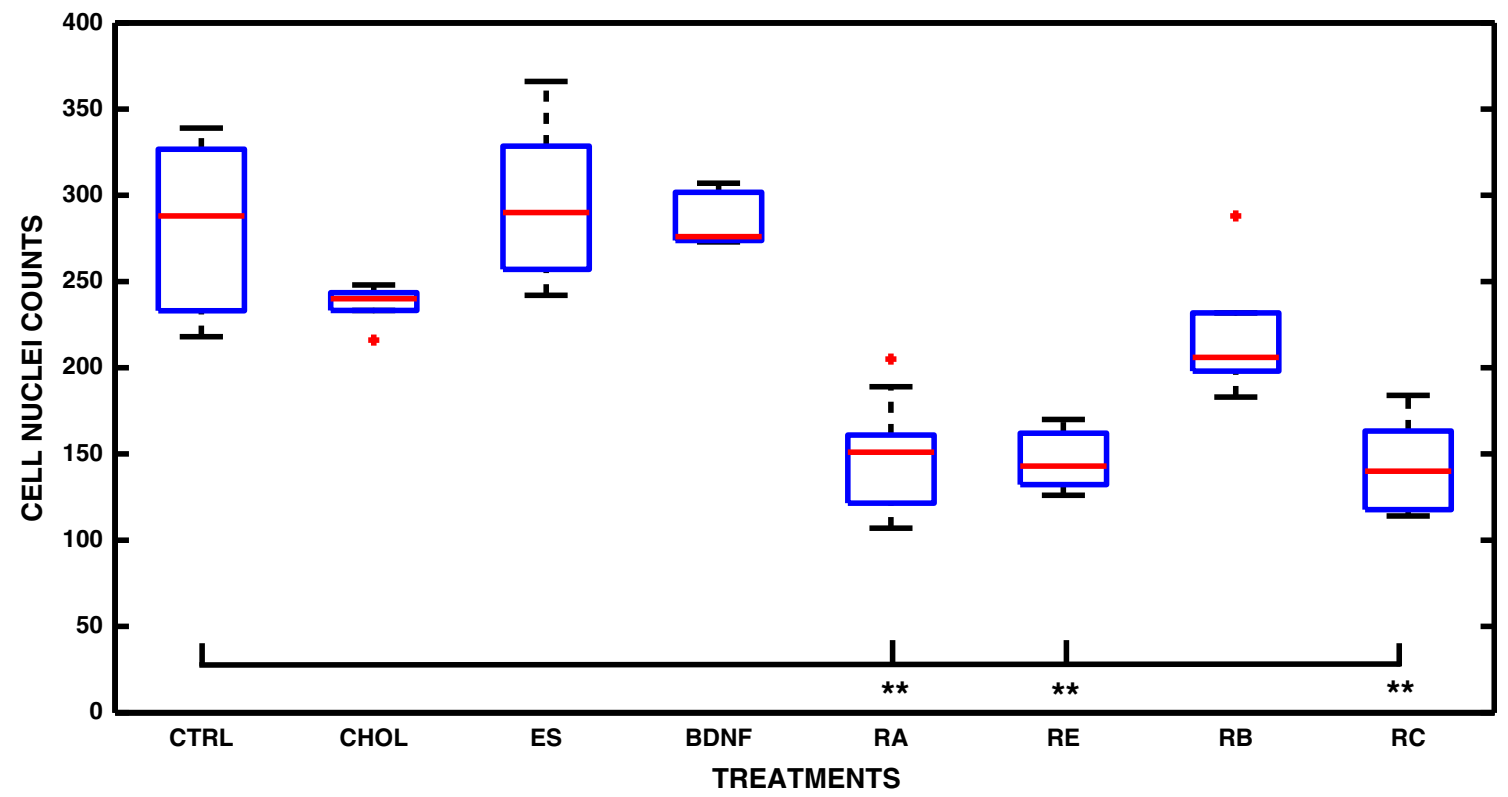

Fig. 2 Inhibition of cell population growth. Cells were cultured in control conditions [CTRL $(n=7)]$, and with CHOL $(n=6), E_{2}$ $(n=6)$, BDNF $(n=6)$, RA $(n=6), \operatorname{RE}(n=6), \operatorname{RB}(n=6)$, and $\mathrm{RC}(\mathrm{n}=8)$ ( $\mathrm{n}$ is the number of analyzed microscopy images) and the cell nuclei were counted at 10 DIV. In the boxplot representation the obtained median nuclei counts, 25th and 75th percentiles, extreme data points, and outliers of the data are shown with red line, blue edges, black whiskers, and red asterisks, respectively. Each differentiation agent is shown on the $\mathrm{x}$-axis and the cell nuclei counts on the y-axis. The statistically significant differences $(p<0.01)$ are shown with asterisks $(* *)$. Significantly lower cell numbers were detected when cells were treated with RA, RE, or RC in comparison to CTRL data. Slight increase in cell numbers (nuclei counts) were observed when cells were treated with $\mathrm{RB}$, in comparison to the cells treated solely with RA. The nuclei counts of RB treated cultures were not significantly lower in comparison to CTRL (Color figure online) 


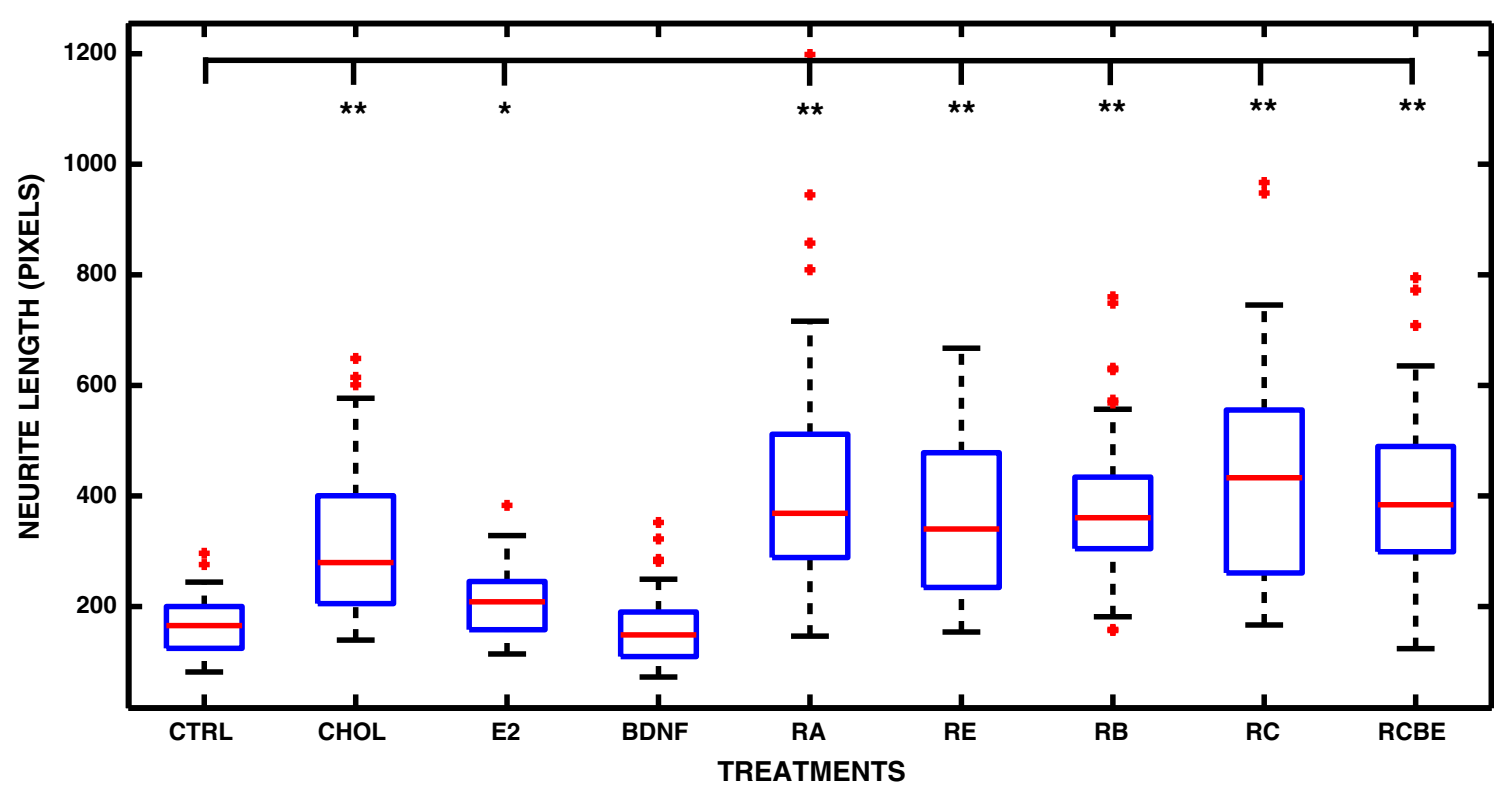

Fig. 3 Neurite lengths in SH-SY5Y cells. Cells were cultured in CTRL conditions, and with CHOL, $\mathrm{E}_{2}, \mathrm{BDNF}, \mathrm{RA}$, or with their combinations; RE, RB, RC, RCBE. In the boxplot representation the obtained median of neurite lengths, the 25 th and 75 th percentiles, the extreme data points, and the outliers of the data are shown with red line, blue edges, black whiskers and red asterisks, respectively. Each treatment is shown on $\mathrm{x}$-axis and the neurite lengths in pixels on $\mathrm{y}$-axis. The statistically significant differences $(p<0.01)$ and

combination treatments such as RE, RB, RC, RCBE $[p<0.01(* *)]$ relative to control conditions (Fig. 3). With the BDNF treatment alone no increase in the neurite length was detected.

\section{Presence of Neurofilaments in SH-SY5Y Neuroblastoma Cells}

The level of differentiation of the SH-SY5Y neuroblastoma cells at 10 DIV was further verified by imaging the NF-68 neurofilaments. The neurofilament fluorescence was defined by visual inspection and by measuring the intensity of CTNF, when cells were treated solely with RA, BDNF, CHOL, or $\mathrm{E}_{2}$ (Fig. 4b-e, respectively) or in combination with RA and $E_{2}$ (RE), RA and BDNF (RB), RA and CHOL (RC), and RA, CHOL, BDNF, and $\mathrm{E}_{2}$ (RCBE) (Fig. 4g-j, respectively). Both visual and automated image analyses showed that the presence of the NF-68 neurofilaments was clearly induced by RA (Fig. 4b). No major increase in NF68 fluorescence levels was observed visually or automatically, when cells were treated with BDNF, CHOL or $\mathrm{E}_{2}$ (Fig. $4 \mathrm{c}-\mathrm{e}$ ). However, the intensity of NF-68 fluorescence was significantly increased in all of the combination treatments relative to control cells, as shown in Fig. $4 \mathrm{~g}-\mathrm{j}$, and in Fig. 5 for RA $[p<0.01(* *)], \operatorname{RE}\left[p<0.05\left(^{*}\right)\right]$, $\mathrm{RC}[p<0.01(* *)], \quad \mathrm{RB} \quad[p<0.01(* *)]$ and $\mathrm{RCBE}$ $[p<0.01(* *)]$. $(p<0.05)$ are shown with asterisks $(* *)$ and $(*)$, respectively. The neurite lengths were significantly longer when cells are treated with RA, CHOL, RE, RB, RC, and RCBE $(p<0.01)$. Interestingly, at 10 DIV, $E_{2}$ induces only short neurites, but the increase in the neurite length is still significant in comparison to controls $(p<0.05)$. Moreover, RA induces significantly longer neurites when compared to $\mathrm{CHOL}$ or $\mathrm{E}_{2}$ induced neurite lengths $(p<0.01)$ (Color figure online)

\section{Differentiation-Induced Synaptic Vesicle Recycling}

Our group has earlier shown that RA and RC treated human SH-SY5Y cells show intense Synaptophysin I (SypI) fluorescence in cell somata, along the neurites and at the sites of the cell-to-cell contacts. Furthermore, we have shown co-localization of SypI and AM1-43 at the end of the neurites at the cell-to-cell contacts of the RA and RC differentiated and high $\mathrm{K}^{+}$depolarized human SH-SY5Y cells [23]. It has been also shown elsewhere that the SHSY5Y cells are capable of depolarization with high $\mathrm{K}^{+}$ stimulation [87]. Therefore, high $\mathrm{K}^{+}$stimulation was used for studying the stimulation-related synaptic vesicle recycling also in this study. The SH-SY5Y neuroblastoma cells were incubated with $\mathrm{E}_{2}, \mathrm{CHOL}, \mathrm{BDNF}$, or RA or with their combinations (RE, RB, RC, RCB and RCBE) and stained at 10 DIV with AM1-43, a fluorescent styryl dye (a nerve terminal probe) with the presence of depolarizing high $\mathrm{K}^{+}$Tyrode solution. The number of fluorescent puncta, reflecting the recycling synaptic vesicles, was counted after depolarization (see Fig. 6 and section "Methods"). Treatment with CHOL or BDNF alone does not increase the number of fluorescence puncta in comparison to CTRL. Our data show for the first time, that the treatment with $\mathrm{E}_{2}$ alone $\left[p<0.05\left(^{*}\right)\right.$ ], or RA together with $\mathrm{E}_{2}(\mathrm{RE})$, BDNF (RB), BDNF and CHOL (RBC) or BDNF, CHOL and $\mathrm{E}_{2}$ (RBCE), $[p<0.01(* *)]$ significantly increases the number 
Fig. 4 The presence of NF-68 neurofilaments in SH-SY5Y neuroblastoma cells.

Neurofilaments were detected at 10 DIV by immunostaining of NF-68 (green) and cell nuclei with Hoechst 33258 (blue). ae Combined double staining of neurofilaments and nuclei in the SH-SY5Y cells in control conditions (CTRL), and when treated with RA, BDNF, CHOL and $E_{2}$, show that RA induces NF-68, seen also in the long branching neurites. a, f No NF68 is seen in CTRL. g-j RE, $\mathrm{RB}, \mathrm{RC}$ and RCBE treatments show presence of

neurofilaments similar to those with RA alone (Color figure online)
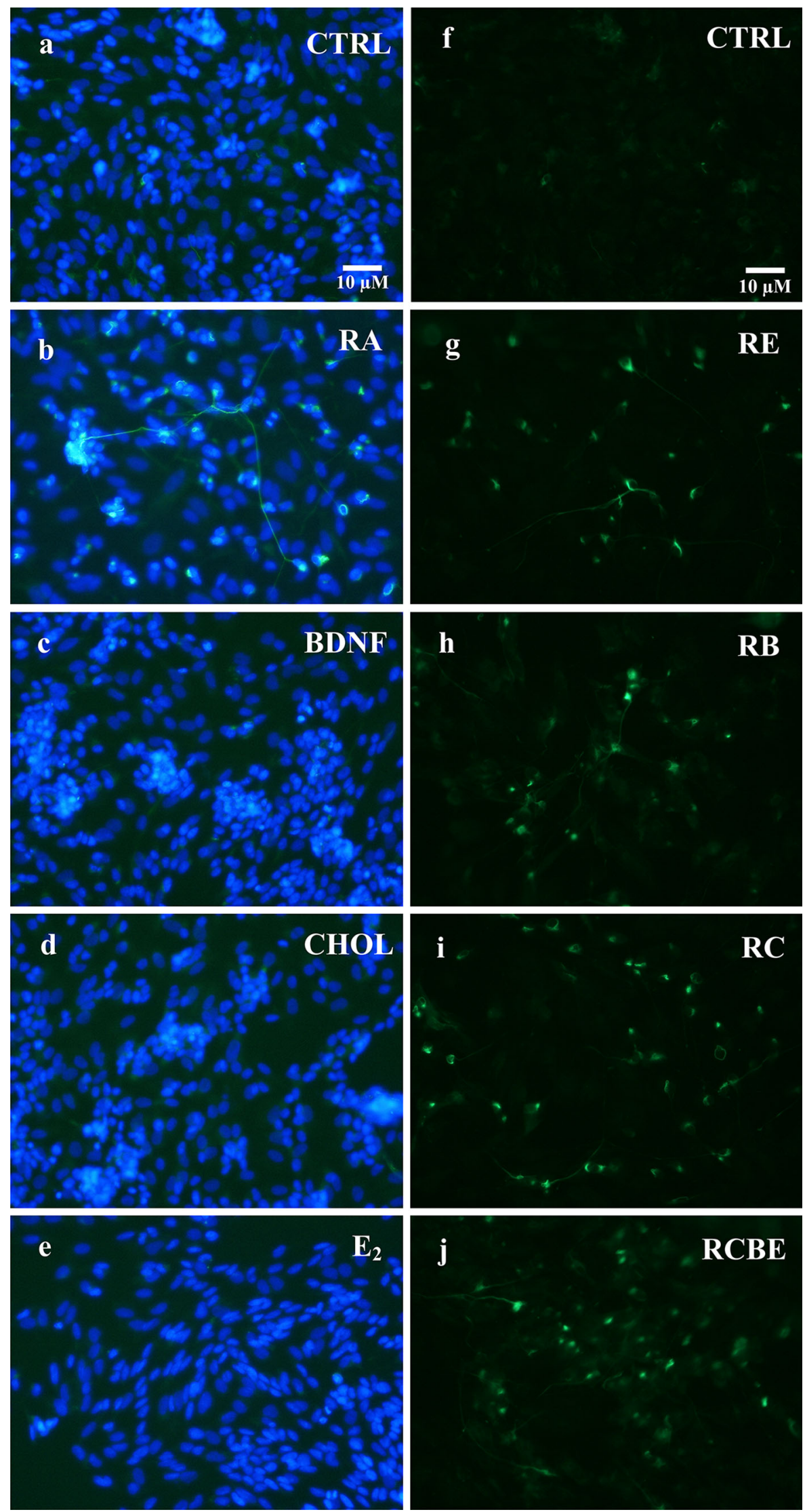


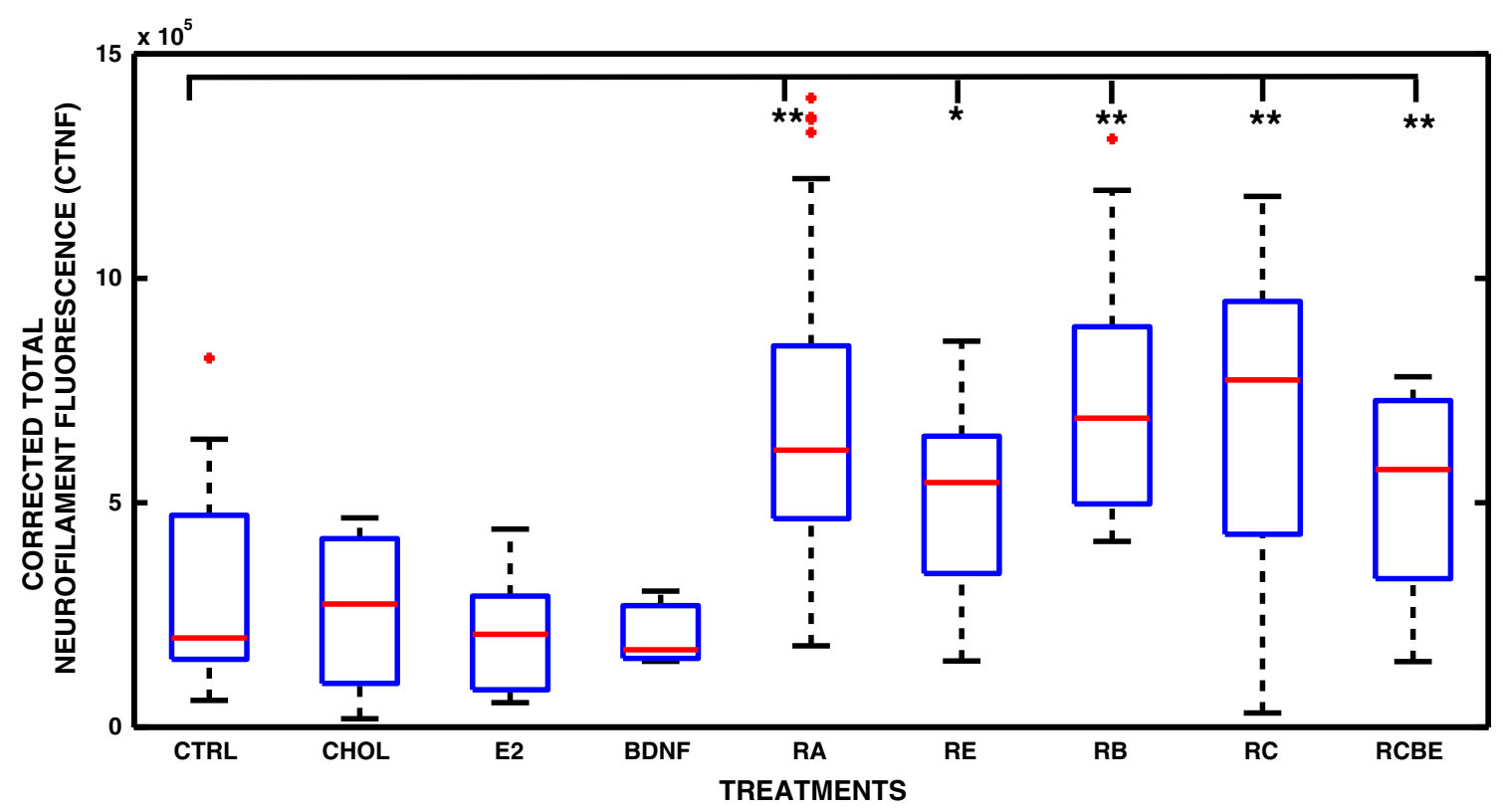

Fig. 5 Corrected total NF-68 neurofilament fluorescence (CTNF). CTNF was analyzed from the control (CTRL) SH-SY5Y cells $(\mathrm{n}=19)$, and cells treated with RA $(\mathrm{n}=38), \mathrm{BDNF}(\mathrm{n}=6), \mathrm{CHOL}$ $(n=6)$ and $E_{2}(n=6)$ and $R C(n=9), R B(n=14), \operatorname{RE}(n=13)$ and $\operatorname{RCBE}(\mathrm{n}=13)$ ( $\mathrm{n}$ is the number of analyzed images). The obtained median of CTNF, the 25th and 75th percentiles, the extreme data points, and the outliers of the data are shown in the boxplot with red line, blue edges, black whiskers and red asterisks, respectively. Differentiation agents are shown on the x-axis and the CTNF on the

of fluorescence puncta when compared to controls. The results also confirm earlier results from our laboratory that RA alone, as well as together with CHOL, significantly $[p<0.01(* *)]$ increases the number of AM1-43 fluorescence puncta in SH-SY5Y cells. This data also indicate a slight, however not significant, increase in fluorescence puncta in CHOL treated cultures, but not in BDNF treated cultures. In particular, we found a significant $[p<0.05(*)]$ increase in cells treated with RCB or RCBE relative to cultures treated without $\mathrm{CHOL}$ (such as RB or RE). These results demonstrate that in addition to RA and CHOL, also prolonged treatment with $\mathrm{E}_{2}$ alone stimulates the synaptic vesicle recycling in SH-SY5Y cells. Highest numbers of fluorescence puncta were detected when all agents were combined (RCBE).

\section{Discussion}

Despite active research for improving the prognosis of high-risk neuroblastoma patients over the last decades, only a few patients become long-term survivors. Outcome of the stage 4 neuroblastoma remains poor, and the development of novel therapeutic approaches is needed [28, 88-91]. Therefore, therapies such as induced y-axis. The statistical differences between the CTNF data and control values are shown with asterisks $\left[p<0.05(*)\right.$, and $\left.p<0.01\left(^{* *}\right)\right]$. The automated analysis confirmed that the CTNF was significantly $[p<0.01(* *)]$ increased in all other RA treated cultures (RA, RB, $\mathrm{RC}, \mathrm{RCB}$, and RCBE) in comparison to control cultures, except increased with less significance in the $\mathrm{RE}$ treated cultures $[p<0.05(*)]$. This data show that NF-68 neurofilaments were induced by RA and further maintained by $\mathrm{CHOL}, \mathrm{BDNF}$ and $\mathrm{E}_{2}$ (Color figure online)

differentiation of cancer cells are important. Retinoic acid is one of the most prominent inducer of differentiation in clinical treatments $[28,90]$. Therefore, in the current study, the level of differentiation of human SH-SY5Y cells towards neuronal type was followed by analyzing the additive impacts of estradiol $\left(\mathrm{E}_{2} / \mathrm{E}\right)$ and brain-derived neurotrophic factor $(\mathrm{BDNF} / \mathrm{B})$ on cell morphology, neurite length, presence of neurofilaments, cell population growth and synaptic vesicle recycling in non-treated controls, as well as retinoic acid (RA/R) and cholesterol ( $\mathrm{CHOL} / \mathrm{C})$ treated cells at 10 days in vitro.

We here confirm our earlier data [23] that the most potent inducer for differentiation is retinoic acid, especially with co-treatment with CHOL. Of the four markers of differentiation (cell population growth, neurite length, total NF-68 fluorescence and synaptic vesicle recycling) growth is inhibited only when RA is present. Estradiol $\left(E_{2}\right)$, a predominant form of estrogen hormone, as well as $\mathrm{CHOL}$, supports this inhibition. Growth rate of the cells treated with RA together with BDNF (RB) was higher than those, which were treated with RA alone. BDNF thus opposes the possibility of cells to undergo RA induced growth inhibition. Earlier results by other laboratories of the impact of BDNF, and in particular of the treatment together with RA, have given controversial results. While some studies show 

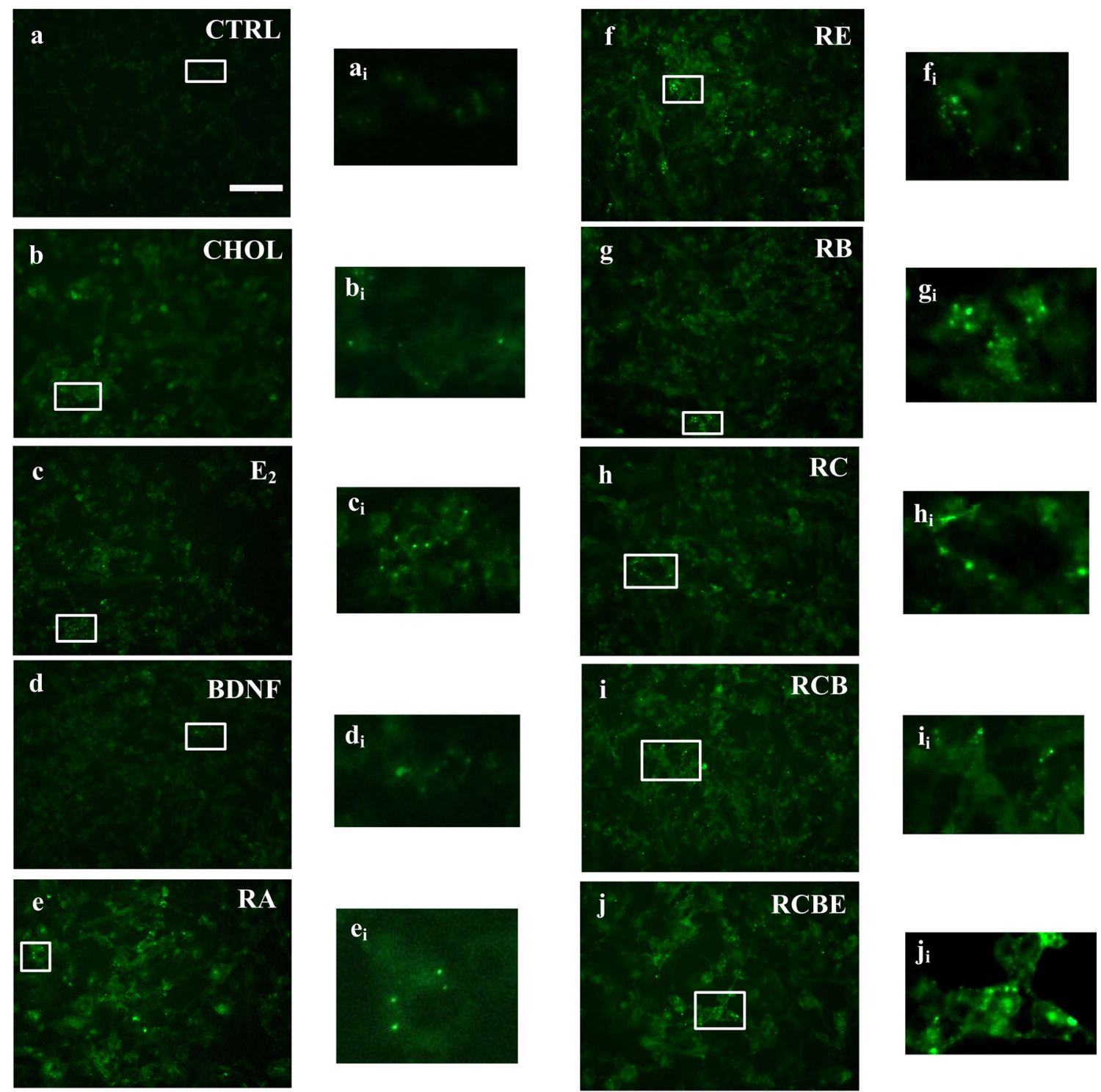

k

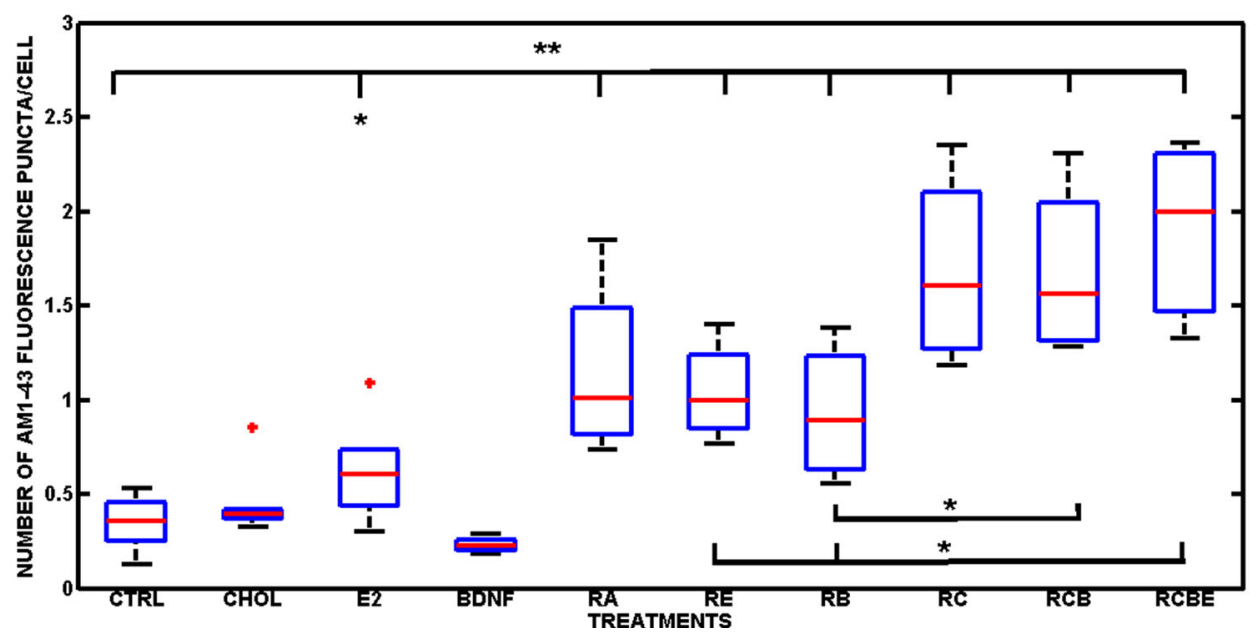


4Fig. 6 Synaptic vesicle recycling in SH-SY5Y neuroblastoma cells. a-j Synaptic vesicle recycling was measured by AM1-43 immunostaining in the presence of depolarizing high $\mathrm{K}^{+}$containing Tyrode solution from control cells [CTRL $(n=12)]$ and cells treated with CHOL $(n=6), E_{2}(n=6), \operatorname{BDNF}(n=6), \operatorname{RA}(n=6)$, or with their combinations such as $\operatorname{RE}(n=6), \operatorname{RB}(n=6), \operatorname{RC}(n=6), \operatorname{RCB}$ $(n=6)$, or RCBE, $(n=9)$ at 10 DIV ( $n$ is the number of analyzed images). $\mathbf{a}_{\mathbf{i}}-\mathbf{j}_{\mathbf{i}}$ Magnified examples of every treatment are shown. k Number of detected fluorescence puncta. In the boxplot, the obtained median number of fluorescence puncta, the 25th and 75th percentiles, the extreme data points, and the outliers of the data are shown with red line, blue edges, black whiskers and red asterisks, respectively. Differentiation agents are shown on the x-axis and the number of AM1-43 fluorescence puncta per obtained median nuclei number on the y-axis. The statistical differences between the data of interest and control values are shown as asterisks $\left[p<0.05\left(^{*}\right)\right.$, and $p<0.01(* *)]$. The number of fluorescence puncta did not significantly increase in comparison to CTRL group, when cells were treated solely with $\mathrm{CHOL}$ or $\mathrm{BDNF}(\mathbf{b}, \mathbf{d}, \mathbf{k}) . \mathrm{E}_{2}$ induced significant increase $\left[p<0.05\left(^{*}\right)\right]$ in the number of AM1-43 puncta relative to control group $(\mathbf{c}, \mathbf{k})$. The results show that RA alone, as well as RE, $\mathrm{RB}, \mathrm{RC}, \mathrm{RCB}$, and RCBE significantly $[p<0.01(* *)]$ increased the number of AM1-43 puncta relative to control group (e-j). Additionally, the synaptic vesicle recycling was significantly $[p<0.05(*)]$ increased when cholesterol was present (in RCB and RCBE treated cultures) when compared to $\mathrm{RB}$ or RE treated groups without $\mathrm{CHOL}$ (k). The highest median of number of fluorescence puncta was detected when neuroblastoma cells were treated with all substances simultaneously (RCBE) (Color figure online)

that the RB treatment differentiated the SH-SY5Y cells $[18,19,37]$, other studies show that the activation of TrkBBDNF pathway, which is also activated by RB treatment, can lead to increased cell survival, invasion, metastasis, angiogenesis and drug resistance [92-96]. Our results of population growth of $\mathrm{RB}$ treated cells are in agreement with the study by Cernaianu et al. [6], showing that the effect on proliferation depends on the used concentration of BDNF, causing either significant inhibition (with $10 \mathrm{ng}$ / $\mathrm{mL}$ BDNF) or no inhibition (with 50 or $100 \mathrm{ng} / \mathrm{mL}$ ) and with the study by Nishida et al. [97], where they show that SH-SY5Y-A cells (American Type Culture Collection; also used in this study) differentiated in the presence of RA whereas RA treated SH-SY5Y-E cells (European Collection of Cell Cultures) require additional BDNF treatment for full differentiation. This is due to the defects in several signaling pathways in SH-SY5Y-E cells. In conclusion, the controversial results in the level of differentiation in some of the studies might originate from the different subtypes of SH-SY5Y, as well as from the used BDNF concentrations. In the light of the current knowledge further examinations of the properties of BDNF are needed, before considering the use of BDNF as a therapeutic agent for clinical use.

Long neurites, typical of neuronal morphology, are found with treatment by retinoic acid, as well as by cholesterol. We here show, that $\mathrm{E}_{2}$ alone (at $1 \mathrm{nM}$ concentration) is able to slightly increase the length of neurites, and when it is combined with RA (RE) or additionally with CHOL and BDNF (RCBE) neurites' length is even more enhanced involving also branching and network formation. It has been earlier demonstrated by Takahashi et al. [98], that $10 \mathrm{nM} \mathrm{E}_{2}$ induces neurite outgrowth already after 2 DIV, which was not seen in this study. This difference in the presence of neurites may be explained by the 10 times difference in the $\mathrm{E}_{2}$ concentrations used. With treatment by BDNF alone, no neurite outgrowth at 10 DIV was detected. This result is understandable based on other reports that 3-5 days' RA treatment is necessary to induce expression of TrkB receptors, which are crucial for BDNF induced neurite growth [18, 37]. Agholme et al. [24] have shown, that the RB and RCB treatments induced longer neurites than treatment with RA alone, which were not seen in our experiments. We additionally show, similarly to the results shown in previous studies, that RA alone $[16,23,99]$ or when combined with CHOL (RC) [23], BDNF (RB) [100], or CHOL and BDNF (RCB) [24] induce considerable neurite outgrowth and neuronal networks.

Neurofilaments are major components of the neuronal cytoskeleton, providing structural support for the axons and regulating the axon's diameter. We here show that treatment with RA alone enhances the total light neurofilament (NF-68) fluorescence. Earlier study from Messi et al. [101] is in agreement with our results by showing that RA reduces cell migration and invasiveness and up regulates NF-68 expression. In addition, it has been shown that medium size neurofilaments (NF-145-160) are induced by RA in SH-SY5Y cells [102]. We detected that RA combined to $E_{2}$ enhanced the total NF-68 fluorescence, though less than the RC, RB, RCB or RCBE treatments. The enhancement of total NF-68 fluorescence in human SHSY5Y cells by these treatments has not been previously reported.

Finally, we asked if RA, $\mathrm{E}_{2}$, CHOL and BDNF or their combinations increase the synaptic vesicle recycling in $\mathrm{SH}-$ SY5Y cells. Results from the current study are interesting, as in addition to RA, also $\mathrm{E}_{2}$, even when used alone, is able to significantly increase the number of detected vesicle recycling after depolarizing cells by high $\mathrm{K}^{+}$-solution. $\mathrm{Hu}$ et al. [103] have shown in cultured neonatal rat cortical primary cells that $E_{2}$, produced and secreted by astrocytes, modulates synaptogenesis and synaptic function by increasing the synaptic vesicle recycling. In addition, they showed that added exogenic estradiol mimics this effect of astrocyte-conditioned medium on synaptic formation and transmission. Our results here are in agreement with this study. Chamniansawat and Chongthammakun [48] have shown that $48 \mathrm{~h}$ estrogen treatment significantly increases the expression of synapse related proteins, such as postsynaptic dense material 95 (PSD-95) and synaptophysin (SYP). As they did not see any estrogen induced immediate 
or rapid effects on the PSD-95 and SYP mRNA expression in SH-SY5Y cells, they concluded that the expressions of PSD-95 and SYP requires translocalization across ER, as well as long period of time to activate the target gene expression in SH-SY5Y cells. This is called classical genomic action of estrogen, where estrogen partially acts through PI-3K signaling to activate PSD-95 and SYP expression. Our data support the hypothesis that prolonged treatment of $\mathrm{E}_{2}$ enhances endo/exocytosis and thus promotes synaptic vesicle recycling in SH-SY5Y cells.

In the current study, synaptic vesicle recycling is significantly enhanced in all combination treatments, where cholesterol is present (RC, RCB and RCBE). Earlier it has been shown that the depolarized RC treated cells induced higher number of AM1-43 positive fluorescence puncta/ cell in comparison to depolarized RA treated cells [23]. We now show for the first time that this same supra-additive effect can be observed in addition to depolarized RC treated cultures also in depolarized RCB and RCBE treated cultures. Sarkanen et al. [23] found that one aspect possibly explaining this effect of RA and CHOL is that the RAinduced fragmentation of Golgi apparatus is avoided by cotreatment with CHOL. In addition, it has been earlier shown that RA has antioxidant potential and, that RA isomers enhance the expression of genes linked with cholesterol efflux e.g. apoe, abca-1 and abcg-1 proteins in astrocytes [104]. We know also from other earlier studies that synaptogenesis is promoted by cholesterol [30], cholesterol influences multiple aspects of synaptic transmission [105], both presynaptically, by acting on neurotransmitter vesicle fusion [106-108] and postsynaptically, altering neurotransmitter receptor mobility in the membrane [109]. Moreover, it is known that retinoic acid has been shown to function in homeostatic plasticity as a signaling molecule that increases synaptic strength by a protein synthesis-dependent mechanism [110]. It is also known that homeostatic synaptic plasticity may manifest as altered presynaptic transmitter release and vesicle loading properties [111, 112]. All above mentioned studies support our current result of the supra-additive effect of cholesterol and retinoic acid on increasing the number of AM1-43 fluorescence puncta in SH-SY5Y cells when compared to cells treated without CHOL.

Earlier and our results indicate that the formation of new synapses is a complex process requiring the presence of multiple substances simultaneously. Cholesterol is especially important as a component of cellular membranes, regulating membrane structure, fluidity and permeability, and as a precursor for steroid hormones. The increased cholesterol efflux has been shown to impair the LTP at the hippocampal CA1 synapses [34]. This study, together with our results, indicates the importance of cholesterol in regulation of synaptic vesicle recycling, neurotransmission, and regeneration of synapses. Lately, research has also started to focus on the effects of estradiol (estrogen) on formation and activity of synapses. A recent study on adult male rat hippocampal slices shows that estradiol treatment enhances synaptic transmission and LTP via estradiol receptor beta $(\mathrm{ER} \beta)$ stimulation. Estradiol activates the RhoA-GTPase signaling, which causes actin polymerization within dendritic spines. The study suggests that estradiol is able to increase the fast excitatory postsynaptic potentials and causes a reduction in the threshold for lasting synaptic changes. Results of the study further indicate that the estradiol (similarly to RA) activates the synaptic TrkB receptors needed for the effects of the BDNF [113].

It is important to review the capacity of neuroblastoma cells to differentiate into a neuronal cell type and link this differentiation to those factors, which are normally present in neuronal microenvironment. Amongst the various glial cells in central nervous system, astrocytes are known to release cholesterol and growth factors and thus promote different aspects of synapse development [30]. Neurons depend on import of cholesterol via lipoproteins [35] to effectively maintain development of new connections via dendrites, dendritic spines and synapses. The efficacy and stability of the pre-synaptic transmitter release largely depends on presence of cholesterol [32]. It is also known that neurons are able to convert glia-derived cholesterol to steroids, which then promotes synapse formation [114], and that astrocytes, in addition to cholesterol also produce and release estradiol, which enhances neurite growth [115] and increases synapse number and function [103, 116]. In this study, we investigated whether cholesterol or estradiol are able to increase synaptic vesicle recycling in human SH-SY5Y cells, and it was found that estradiol, even alone, is able to promote synaptic vesicle recycling in these cells. Cholesterol, in contrast, does that only when used together with retinoic acid. Our results indicate the importance of estradiol, cholesterol and retinoic acid in synaptic function.

The findings reported here have significance for understanding the effects of retinoic acid, cholesterol, estradiol and brain derived neurotrophic factor, either alone or in combinations in the process of SH-SY5Y neuroblastoma cell differentiation into neuronal cell type. More than one agent is clearly necessary to reach this goal in aim to benefit the differentiation induced therapies.

Acknowledgments The authors acknowledge the financial support from Tampere University of Technology President's Doctoral Programme, Finnish Foundation for Technology Promotion, Finnish Cultural Foundation, Pirkanmaa Regional fund, Tampere Doctoral Programme in Information Science and Engineering. The research leading to these results has received partial funding from the European Union Seventh Framework Programme (FP7) under grant agreement $n^{\circ} 604102$ (HBP). Furthermore the authors want to thank 
Professor Timo Ylikomi for providing research facilities, Ms. Mirja Hyppönen, Ms. Hilkka Mäkinen and Ms. Paula Helpiölä for their technical support.

\section{Compliance with Ethical Standards}

Conflict of Interest The authors declare that they have no conflict of interest.

Ethical Approval This article does not contain any studies with human participants or animals performed by any of the authors. For this type of study formal consent is not required.

Open Access This article is distributed under the terms of the Creative Commons Attribution 4.0 International License (http://crea tivecommons.org/licenses/by/4.0/), which permits unrestricted use, distribution, and reproduction in any medium, provided you give appropriate credit to the original author(s) and the source, provide a link to the Creative Commons license, and indicate if changes were made.

\section{References}

1. Duckett JW, Koop CE (1977) Neuroblastoma. Urol Clin N Am 4:285-295

2. Franks LM, Bollen A, Seeger RC et al (1997) Neuroblastoma in adults and adolescents: an indolent course with poor survival. Cancer 79:2028-2035

3. Escobar MA, Grosfeld JL, Powell RL et al (2006) Long-term outcomes in patients with stage IV neuroblastoma. J Pediatr Surg 41:377-381

4. Biedler JL, Helson L, Spengler BA (1973) Morphology and growth, tumorigenicity, and cytogenetics of human neuroblastoma cells in continuous culture. Cancer Res 33:2643-2652

5. Kuramoto T, Werrbach-Perez K, Perez-Polo JR et al (1981) Membrane properties of a human neuroblastoma II: effects of differentiation. J Neurosci Res 6:441-449

6. Cernaianu G, Brandmaier P, Scholz G et al (2008) All-trans retinoic acid arrests neuroblastoma cells in a dormant state. Subsequent nerve growth factor/brain-derived neurotrophic factor treatment adds modest benefit. J Pediatr Surg 43:1284-1294

7. Tojima T, Kobayashi S, Ito E (2003) Dual role of cyclic AMPdependent protein kinase in neuritogenesis and synaptogenesis during neuronal differentiation. J Neurosci Res 74:829-837

8. Pahlman S, Odelstad L, Larsson E et al (1981) Phenotypic changes of human neuroblastoma cells in culture induced by 12-O-tetradecanoyl-phorbol-13-acetate. Int $\mathrm{J}$ Cancer 28: 583-589

9. Pahlman S, Ruusala AI, Abrahamsson L et al (1984) Retinoic acid-induced differentiation of cultured human neuroblastoma cells: a comparison with phorbolester-induced differentiation. Cell Differ 14:135-144

10. Adem A, Mattsson ME, Nordberg A et al (1987) Muscarinic receptors in human SH-SY5Y neuroblastoma cell line: regulation by phorbol ester and retinoic acid-induced differentiation. Brain Res 430:235-242

11. Jalonen T, Akerman KE (1988) Single transient potassium channels in human neuroblastoma cells induced to differentiate in vitro. Neurosci Lett 86:99-104

12. Guarneri P, Cascio C, Piccoli T et al (2000) Human neuroblastoma SH-SY5Y cell line: neurosteroid-producing cell line relying on cytoskeletal organization. J Neurosci Res 60:656-665

13. Presgraves SP, Ahmed T, Borwege S et al (2004) Terminally differentiated SH-SY5Y cells provide a model system for studying neuroprotective effects of dopamine agonists. Neurotox Res 5:579-598

14. Preis PN, Saya H, Nadasdi L et al (1988) Neuronal cell differentiation of human neuroblastoma cells by retinoic acid plus herbimycin A. Cancer Res 48:6530-6534

15. Toselli M, Tosetti P, Taglietti V (1996) Functional changes in sodium conductances in the human neuroblastoma cell line $\mathrm{SH}-$ SY5Y during in vitro differentiation. J Neurophysiol 76:3920-3927

16. Cheung YT, Lau WK, Yu MS et al (2009) Effects of all-transretinoic acid on human SH-SY5Y neuroblastoma as in vitro model in neurotoxicity research. Neurotoxicology 30:127-135

17. Spina MB, Squinto SP, Miller J et al (1992) Brain-derived neurotrophic factor protects dopamine neurons against 6-hydroxydopamine and N-methyl-4-phenylpyridinium ion toxicity: involvement of the glutathione system. J Neurochem 59:99-106

18. Encinas M, Iglesias M, Liu Y et al (2000) Sequential treatment of SH-SY5Y cells with retinoic acid and brain-derived neurotrophic factor gives rise to fully differentiated, neurotrophic factor-dependent, human neuron-like cells. J Neurochem 75: 991-1003

19. Goldie BJ, Barnett MM, Cairns MJ (2014) BDNF and the maturation of posttranscriptional regulatory networks in human SH-SY5Y neuroblast differentiation. Front Cell Neurosci 8:325

20. Rogers MV, Buensuceso C, Montague F et al (1994) Vanadate stimulates differentiation and neurite outgrowth in rat pheochromocytoma PC12 cells and neurite extension in human neuroblastoma SH-SY5Y cells. Neuroscience 60:479-494

21. Lavenius E, Gestblom C, Johansson I et al (1995) Transfection of TRK-A into human neuroblastoma cells restores their ability to differentiate in response to nerve growth factor. Cell Growth Differ 6:727-736

22. Oe T, Sasayama T, Nagashima $T$ et al (2005) Differences in gene expression profile among SH-SY5Y neuroblastoma subclones with different neurite outgrowth responses to nerve growth factor. J Neurochem 94:1264-1276

23. Sarkanen JR, Nykky J, Siikanen J et al (2007) Cholesterol supports the retinoic acid-induced synaptic vesicle formation in differentiating human SH-SY5Y neuroblastoma cells. J Neurochem 102:1941-1952

24. Agholme L, Lindstrom T, Kagedal K et al (2010) An in vitro model for neuroscience: differentiation of SH-SY5Y cells into cells with morphological and biochemical characteristics of mature neurons. J Alzheimers Dis 20:1069-1082

25. Szutowicz A, Bielarczyk H, Jankowska-Kulawy A et al (2015) Retinoic acid as a therapeutic option in Alzheimer's disease: a focus on cholinergic restoration. Expert Rev Neurother 15:239-249

26. Sidell N, Lucas CA, Kreutzberg GW (1984) Regulation of acetylcholinesterase activity by retinoic acid in a human neuroblastoma cell line. Exp Cell Res 155:305-309

27. Stio M, Celli A, Treves C (2001) Synergistic anti-proliferative effects of vitamin $\mathrm{D}$ derivatives and 9-cis retinoic acid in $\mathrm{SH}-$ SY5Y human neuroblastoma cells. J Steroid Biochem Mol Biol 77:213-222

28. Matthay KK, Reynolds CP, Seeger RC et al (2009) Long-term results for children with high-risk neuroblastoma treated on a randomized trial of myeloablative therapy followed by 13-cisretinoic acid: a children's oncology group study. J Clin Oncol 27:1007-1013

29. Adamson PC, Matthay KK, O'Brien M et al (2007) A phase 2 trial of all-trans-retinoic acid in combination with interferonalpha2a in children with recurrent neuroblastoma or wilms tumor: a pediatric oncology branch, NCI and children's oncology group study. Pediatr Blood Cancer 49:661-665

30. Mauch DH, Nagler K, Schumacher S et al (2001) CNS synaptogenesis promoted by glia-derived cholesterol. Science 294:1354-1357 
31. Chen J, Costa LG, Guizzetti M (2011) Assessment of cholesterol homeostasis in astrocytes and neurons. Methods Mol Biol 758:403-414

32. Goritz C, Mauch DH, Pfrieger FW (2005) Multiple mechanisms mediate cholesterol-induced synaptogenesis in a CNS neuron. Mol Cell Neurosci 29:190-201

33. Ullian EM, Harris BT, Wu A et al (2004) Schwann cells and astrocytes induce synapse formation by spinal motor neurons in culture. Mol Cell Neurosci 25:241-251

34. Koudinov AR, Koudinova NV (2001) Essential role for cholesterol in synaptic plasticity and neuronal degeneration. FASEB J 15:1858-1860

35. Pfrieger FW (2003) Outsourcing in the brain: do neurons depend on cholesterol delivery by astrocytes? BioEssays 25:72-78

36. Huang EJ, Reichardt LF (2001) Neurotrophins: roles in neuronal development and function. Annu Rev Neurosci 24:677-736

37. Kaplan DR, Matsumoto K, Lucarelli E et al (1993) Induction of TrkB by retinoic acid mediates biologic responsiveness to BDNF and differentiation of human neuroblastoma cells. Eukaryotic signal transduction group. Neuron 11:321-331

38. Ho R, Eggert A, Hishiki T et al (2002) Resistance to chemotherapy mediated by TrkB in neuroblastomas. Cancer Res 62:6462-6466

39. Low WC, Rujitanaroj PO, Wang F et al (2015) Nanofiber-mediated release of retinoic acid and brain-derived neurotrophic factor for enhanced neuronal differentiation of neural progenitor cells. Drug Deliv Transl Res 5:89-100

40. Ferrer I, Goutan E, Marin C et al (2000) Brain-derived neurotrophic factor in huntington disease. Brain Res 866:257-261

41. Murer MG, Yan Q, Raisman-Vozari R (2001) Brain-derived neurotrophic factor in the control human brain, and in Alzheimer's disease and Parkinson's disease. Prog Neurobiol 63:71-124

42. Phillips HS, Hains JM, Armanini M et al (1991) BDNF mRNA is decreased in the hippocampus of individuals with Alzheimer's disease. Neuron 7:695-702

43. Gould E, Woolley CS, Frankfurt M et al (1990) Gonadal steroids regulate dendritic spine density in hippocampal pyramidal cells in adulthood. J Neurosci 10:1286-1291

44. McEwen BS, Coirini H, Schumacher M (1990) Steroid effects on neuronal activity: When is the genome involved? Ciba Found Symp 153:3-12 (discussion 12-21)

45. Woolley CS, Gould E, Frankfurt M et al (1990) Naturally occurring fluctuation in dendritic spine density on adult hippocampal pyramidal neurons. J Neurosci 10:4035-4039

46. Wong M, Moss RL (1992) Long-term and short-term electrophysiological effects of estrogen on the synaptic properties of hippocampal CA1 neurons. J Neurosci 12:3217-3225

47. Wong M, Moss RL (1991) Electrophysiological evidence for a rapid membrane action of the gonadal steroid, 17 beta-estradiol, on CA1 pyramidal neurons of the rat hippocampus. Brain Res 543:148-152

48. Chamniansawat S, Chongthammakun S (2009) Estrogen stimulates activity-regulated cytoskeleton associated protein ( $\operatorname{arc})$ expression via the MAPK- and PI-3K-dependent pathways in SH-SY5Y cells. Neurosci Lett 452:130-135

49. Chindewa R, Lapanantasin S, Sanvarinda Y et al (2008) Pueraria mirifica, phytoestrogen-induced change in synaptophysin expression via estrogen receptor in rat hippocampal neuron. J Med Assoc Thai 91:208-214

50. Jelks KB, Wylie R, Floyd CL et al (2007) Estradiol targets synaptic proteins to induce glutamatergic synapse formation in cultured hippocampal neurons: critical role of estrogen receptoralpha. J Neurosci 27:6903-6913

51. Liu F, Day M, Muniz LC et al (2008) Activation of estrogen receptor-beta regulates hippocampal synaptic plasticity and improves memory. Nat Neurosci 11:334-343
52. Xu X, Zhang Z (2006) Effects of estradiol benzoate on learningmemory behavior and synaptic structure in ovariectomized mice. Life Sci 79:1553-1560

53. Babayan AH, Kramar EA (2013) Rapid effects of oestrogen on synaptic plasticity: interactions with actin and its signalling proteins. J Neuroendocrinol 25:1163-1172

54. Kretz O, Fester L, Wehrenberg U et al (2004) Hippocampal synapses depend on hippocampal estrogen synthesis. J Neurosci 24:5913-5921

55. Prange-Kiel J, Wehrenberg U, Jarry H et al (2003) Para/autocrine regulation of estrogen receptors in hippocampal neurons. Hippocampus 13:226-234

56. Woolley CS, McEwen BS (1994) Estradiol regulates hippocampal dendritic spine density via an N-methyl-D-aspartate receptor-dependent mechanism. J Neurosci 14:7680-7687

57. Weiland NG (1992) Estradiol selectively regulates agonist binding sites on the N-methyl-D-aspartate receptor complex in the CA1 region of the hippocampus. Endocrinology 131:662-668

58. Warren SG, Humphreys AG, Juraska JM et al (1995) LTP varies across the estrous cycle: enhanced synaptic plasticity in proestrus rats. Brain Res 703:26-30

59. Good M, Day M, Muir JL (1999) Cyclical changes in endogenous levels of oestrogen modulate the induction of LTD and LTP in the hippocampal CA1 region. Eur $\mathrm{J}$ Neurosci 11:4476-4480

60. Gazzaley AH, Weiland NG, McEwen BS et al (1996) Differential regulation of NMDAR1 mRNA and protein by estradiol in the rat hippocampus. J Neurosci 16:6830-6838

61. Cyr M, Ghribi O, Thibault C et al (2001) Ovarian steroids and selective estrogen receptor modulators activity on rat brain NMDA and AMPA receptors. Brain Res Brain Res Rev 37:153-161

62. Cyr M, Ghribi O, Di Paolo T (2000) Regional and selective effects of oestradiol and progesterone on NMDA and AMPA receptors in the rat brain. J Neuroendocrinol 12:445-452

63. Bi R, Foy MR, Vouimba RM et al (2001) Cyclic changes in estradiol regulate synaptic plasticity through the MAP kinase pathway. Proc Natl Acad Sci U S A 98:13391-13395

64. Cordoba Montoya DA, Carrer HF (1997) Estrogen facilitates induction of long term potentiation in the hippocampus of awake rats. Brain Res 778:430-438

65. Woolley CS, Weiland NG, McEwen BS et al (1997) Estradiol increases the sensitivity of hippocampal CA1 pyramidal cells to NMDA receptor-mediated synaptic input: correlation with dendritic spine density. J Neurosci 17:1848-1859

66. Rudick CN, Woolley CS (2001) Estrogen regulates functional inhibition of hippocampal CA1 pyramidal cells in the adult female rat. J Neurosci 21:6532-6543

67. Smith CC, McMahon LL (2005) Estrogen-induced increase in the magnitude of long-term potentiation occurs only when the ratio of NMDA transmission to AMPA transmission is increased. J Neurosci 25:7780-7791

68. Kuiper GG, Enmark E, Pelto-Huikko M et al (1996) Cloning of a novel receptor expressed in rat prostate and ovary. Proc Natl Acad Sci U S A 93:5925-5930

69. Levin ER (2005) Integration of the extranuclear and nuclear actions of estrogen. Mol Endocrinol 19:1951-1959

70. Akama KT, McEwen BS (2003) Estrogen stimulates postsynaptic density-95 rapid protein synthesis via the akt/protein kinase B pathway. J Neurosci 23:2333-2339

71. Waters EM, Mitterling K, Spencer JL et al (2009) Estrogen receptor alpha and beta specific agonists regulate expression of synaptic proteins in rat hippocampus. Brain Res 1290:1-11

72. Marino M, Galluzzo P, Ascenzi P (2006) Estrogen signaling multiple pathways to impact gene transcription. Curr Genomics 7:497-508 
73. Ivanova T, Mendez P, Garcia-Segura LM et al (2002) Rapid stimulation of the PI3-kinase/akt signalling pathway in developing midbrain neurones by oestrogen. J Neuroendocrinol 14:73-79

74. Mannella P, Brinton RD (2006) Estrogen receptor protein interaction with phosphatidylinositol 3-kinase leads to activation of phosphorylated akt and extracellular signal-regulated kinase $1 / 2$ in the same population of cortical neurons: a unified mechanism of estrogen action. J Neurosci 26:9439-9447

75. Bang OY, Hong HS, Kim DH et al (2004) Neuroprotective effect of genistein against beta amyloid-induced neurotoxicity. Neurobiol Dis 16:21-28

76. Steward O, Worley PF (2001) A cellular mechanism for targeting newly synthesized mRNAs to synaptic sites on dendrites. Proc Natl Acad Sci U S A 98:7062-7068

77. Guzowski JF, Lyford GL, Stevenson GD et al (2000) Inhibition of activity-dependent arc protein expression in the rat hippocampus impairs the maintenance of long-term potentiation and the consolidation of long-term memory. J Neurosci 20:3993-4001

78. Guzowski JF, Setlow B, Wagner EK et al (2001) Experiencedependent gene expression in the rat hippocampus after spatial learning: a comparison of the immediate-early genes arc, c-fos, and zif268. J Neurosci 21:5089-5098

79. Schneider CA, Rasband WS, Eliceiri KW (2012) NIH image to ImageJ: 25 years of image analysis. Nat Methods 9:671-675

80. Gavet O, Pines J (2010) Progressive activation of CyclinB1Cdk1 coordinates entry to mitosis. Dev Cell 18:533-543

81. Burgess A, Vigneron S, Brioudes E et al (2010) Loss of human greatwall results in $\mathrm{G} 2$ arrest and multiple mitotic defects due to deregulation of the cyclin B-Cdc2/PP2A balance. Proc Natl Acad Sci U S A 107:12564-12569

82. Selinummi J, Seppala J, Yli-Harja O et al (2005) Software for quantification of labeled bacteria from digital microscope images by automated image analysis. Biotechniques 39:859-863

83. Fanti Z, De-Miguel FF, Martinez-Perez ME (2008) A method for semiautomatic tracing and morphological measuring of neurite outgrowth from DIC sequences. Conf Proc IEEE Eng Med Biol Soc 2008:1196-1199

84. Croft BG, Fortin GD, Corera AT et al (2005) Normal biogenesis and cycling of empty synaptic vesicles in dopamine neurons of vesicular monoamine transporter 2 knockout mice. Mol Biol Cell 16:306-315

85. Pyle JL, Kavalali ET, Choi S et al (1999) Visualization of synaptic activity in hippocampal slices with FM1-43 enabled by fluorescence quenching. Neuron 24:803-808

86. Biagiotti T, D'Amico M, Marzi I et al (2006) Cell renewing in neuroblastoma: electrophysiological and immunocytochemical characterization of stem cells and derivatives. Stem Cells 24:443-453

87. Daniele F, Di Cairano ES, Moretti S et al (2015) TIRFM and $\mathrm{pH}$-sensitive GFP-probes to evaluate neurotransmitter vesicle dynamics in SH-SY5Y neuroblastoma cells: Cell imaging and data analysis. J Vis Exp (95). doi:10.3791/52267

88. Simon T, Berthold F, Borkhardt A et al (2011) Treatment and outcomes of patients with relapsed, high-risk neuroblastoma: results of german trials. Pediatr Blood Cancer 56:578-583

89. Berthold F, Boos J, Burdach S et al (2005) Myeloablative megatherapy with autologous stem-cell rescue versus oral maintenance chemotherapy as consolidation treatment in patients with high-risk neuroblastoma: a randomised controlled trial. Lancet Oncol 6:649-658

90. Matthay KK, Villablanca JG, Seeger RC et al (1999) Treatment of high-risk neuroblastoma with intensive chemotherapy, radiotherapy, autologous bone marrow transplantation, and 13-cis-retinoic acid. Children's cancer group. N Engl J Med 341:1165-1173

91. Pearson AD, Pinkerton CR, Lewis IJ et al (2008) High-dose rapid and standard induction chemotherapy for patients aged over 1 year with stage 4 neuroblastoma: a randomised trial. Lancet Oncol 9:247-256

92. Nakamura K, Martin KC, Jackson JK et al (2006) Brain-derived neurotrophic factor activation of TrkB induces vascular endothelial growth factor expression via hypoxia-inducible factor-1alpha in neuroblastoma cells. Cancer Res 66:4249-4255

93. Acheson A, Conover JC, Fandl JP et al (1995) A BDNF autocrine loop in adult sensory neurons prevents cell death. Nature 374:450-453

94. Jaboin J, Kim CJ, Kaplan DR et al (2002) Brain-derived neurotrophic factor activation of TrkB protects neuroblastoma cells from chemotherapy-induced apoptosis via phosphatidylinositol 3'-kinase pathway. Cancer Res 62:6756-6763

95. Matsumoto K, Wada RK, Yamashiro JM et al (1995) Expression of brain-derived neurotrophic factor and p145TrkB affects survival, differentiation, and invasiveness of human neuroblastoma cells. Cancer Res 55:1798-1806

96. Nakagawara A, Azar CG, Scavarda NJ et al (1994) Expression and function of TRK-B and BDNF in human neuroblastomas. Mol Cell Biol 14:759-767

97. Nishida Y, Adati N, Ozawa R et al (2008) Identification and classification of genes regulated by phosphatidylinositol 3-kinase- and TRKB-mediated signalling pathways during neuronal differentiation in two subtypes of the human neuroblastoma cell line SH-SY5Y. BMC Res. Notes 1:95-0500-1-95

98. Takahashi K, Piao S, Yamatani H et al (2011) Estrogen induces neurite outgrowth via rho family GTPases in neuroblastoma cells. Mol Cell Neurosci 48:217-224

99. Muley PD, McNeill EM, Marzinke MA et al (2008) The atRAresponsive gene neuron navigator 2 functions in neurite outgrowth and axonal elongation. Dev Neurobiol 68:1441-1453

100. Fryer RH, Kaplan DR, Kromer LF (1997) Truncated trkB receptors on nonneuronal cells inhibit BDNF-induced neurite outgrowth in vitro. Exp Neurol 148:616-627

101. Messi E, Florian MC, Caccia C et al (2008) Retinoic acid reduces human neuroblastoma cell migration and invasiveness: effects on DCX, LIS1, neurofilaments-68 and vimentin expression. BMC Cancer 8:30-2407-8-30

102. Rebhan M, Vacun G, Bayreuther K et al (1994) Altered ganglioside expression by SH-SY5Y cells upon retinoic acid-induced neuronal differentiation. NeuroReport 5:941-944

103. Hu R, Cai WQ, Wu XG et al (2007) Astrocyte-derived estrogen enhances synapse formation and synaptic transmission between cultured neonatal rat cortical neurons. Neuroscience 144:1229-1240

104. Sodhi RK, Singh N (2014) Retinoids as potential targets for Alzheimer's disease. Pharmacol Biochem Behav 120:117-123

105. Pfrieger FW (2003) Role of cholesterol in synapse formation and function. Biochim Biophys Acta 1610:271-280

106. Deutsch JW, Kelly RB (1981) Lipids of synaptic vesicles: relevance to the mechanism of membrane fusion. Biochemistry 20:378-385

107. Linetti A, Fratangeli A, Taverna E et al (2010) Cholesterol reduction impairs exocytosis of synaptic vesicles. J Cell Sci 123:595-605

108. Smith AJ, Sugita S, Charlton MP (2010) Cholesterol-dependent kinase activity regulates transmitter release from cerebellar synapses. J Neurosci 30:6116-6121

109. Renner M, Choquet D, Triller A (2009) Control of the postsynaptic membrane viscosity. J Neurosci 29:2926-2937

110. Aoto J, Nam CI, Poon MM et al (2008) Synaptic signaling by all-trans retinoic acid in homeostatic synaptic plasticity. Neuron 60:308-320 
111. Davis GW (2006) Homeostatic control of neural activity: from phenomenology to molecular design. Annu Rev Neurosci 29:307-323

112. Rich MM, Wenner P (2007) Sensing and expressing homeostatic synaptic plasticity. Trends Neurosci 30:119-125

113. Kramar EA, Babayan AH, Gall CM et al (2013) Estrogen promotes learning-related plasticity by modifying the synaptic cytoskeleton. Neuroscience 239:3-16

114. Fester L, Zhou L, Butow A et al (2009) Cholesterol-promoted synaptogenesis requires the conversion of cholesterol to estradiol in the hippocampus. Hippocampus 19:692-705
115. Nilsen J, Mor G, Naftolin F (1998) Raloxifene induces neurite outgrowth in estrogen receptor positive PC12 cells. Menopause 5:211-216

116. Chen G, Li HM, Chen YR et al (2007) Decreased estradiol release from astrocytes contributes to the neurodegeneration in a mouse model of niemann-pick disease type C. Glia 55:1509_ 1518 